\title{
CATHERINE MALABOU
}

\section{THE BRAIN OF HISTORY OR THE MENTALITY OF THE ANTHROPOCENE}

Abstract: How is it possible to account for the double dimension of the "anthropos" of the Anthropocene ? At once both a responsible, historical subject, and a neutral, non-conscious and non-reflexive force? According to Chakrabarty, the "anthropos" has to be considered a geological force; according to Smail, it has to be considered an addicted brain. A subjectivity without being for the former, an emotional and dependent biological and symbolic entity for the latter. As an in between solution, I propose a rereading of the concept of "mentality" proposed by Braudel and his followers from the Annales School. The mental would be intermediarily located between the inorganic and the neural, thus helping to fill the gap between two opposed concepts of history, that are both implied in the current redefinition of ecology.

Key words : species, brain, mental, numbness, long term temporality

Editor's note : Catherine Malabou is a professor at the Cetre For Research in Modern European Philosophy at Kingston University, UK. Her last book is Before Tomorrow, Epigenesis and Rationality, tbo Polity Press, May 2016.

The present essay is a response to the highly challenging topic on which Ian Baucomb and Matthew Omelski asked me to elaborate : "For your contribution, they wrote, we would be particularly interested in an essay that investigates the intersection of philosophy and neuroscience as it relates to climate change" (pers.comm. october 2015). After some time, I decided to explore the link between the current constitution of the brain as the new subject of history, and the type of awareness requested by the Anthropocene.

An immediate answer to Baucomb's and Omelski's challenge would have been the exploration of relationship between the brain and the "environment". It is of course a widespread idea in global change literature that "the Antropocene idea abolishes the break between nature and culture, between human history and the history of life and earth" (Bonneuil, Fressoz $2016: 19$ ), that is also between "environment and society" (Bonneuil, Fressoz 2016 : 37). The blurring of these frontiers of course necessitates to study the profound interaction between the sociological and the ecological, and to see them as parts of he same metabolism. I believe this notion of "interaction" to need a closer analysis though, and to render necessary a preliminary analysis of the specific concept of history in which it currently takes place.

If the Anthropocene acquires the status of a true geological epoch, it is obvious that such an epoch will determine the historical representation as well as the social and political meaning of the 
events occurring in it. In other terms, this new geological era will not and cannot have the neutrality and a-subjectivity characteristic of geological eras in general.

The Anthropocene situates the human being itself between nature and history. On the one hand, it is still of course the subject of its own history, responsible, and conscious. Consciousness of history, or "historicity", is not separable from history itself. It entails memory, capacity to change, and, precisely, responsibility. On the other hand though, the human of the Anthropocene, defined as a geological force, must be as neutral and indifferent as geological reality itself. The two sides of this new identity cannot mirror each other, which causes a break in reflexivity.

The awareness of the Anthropocene then originates in an interruption of consciousness. Such is the problem. I intend to ask whether such an interruption opens or not the space for a substitution of the brain for consciousness. I will proceed to a confrontation between two different points of view on this question. According to the first, the Anthropocene forces us to consider the human as a geological agent purely and simply. Such is Dipesh Chakrabarty's position. I will refer to his two now famous articles (Chakrabarty 2009, 2012). According to the second, understanding the Anthropocene necessarily leads to confer a central role to the brain, and thus to biology. This approach is that of Daniel Smail as developed in his book On Deep History and the Brain (Smail 2008). I will show how their two approaches may be seen as complementing one another, and will introduce in the debate, as a medium term and under a new form, some important and unjustly forgotten elements brought to light by some prominent French historians from the Ecoles des Annales - like those of "mentality" and "slow" or "long term" temporality.

Chakrabarty denies any metaphorical understanding of the "geological". If the human has become a geological form, there has to exist somewhere, at a certain level, an isomorphy, or structural sameness, between humanity and geology. This isomorphy is what emerges - at least in the form of a question — when consciousness, precisely, gets interrupted by this very fact. Human subjectivity, as geologized so to speak, is broken in at least two parts, revealing the split between an agent endowed with free will and the capacity to self-reflect, and a neutral inorganic power, which paralyzes the energy of the former. Once again, we are not facing here the dichotomy between the historical and the biological, we are not dealing with the relationship between man understood as a living being and man understood as a subject.

Man cannot appear to itself as a geological force, because being a geological force is a mode of disappearance. Therefore, the becoming force of the human is beyond any phenomenology, 
and has no ontological status. Human subjectivity is in a sense reduced to atoms without any atomic intention, and has become structurally alien, by want of reflexivity, to its own apocalypse.

A major common point between Chakrabarty and Smail is the necessity to consider that history does not start with recorded history, but has to be envisaged as deep history. Chakrabarty declares: "species thinking (...) is connected to the enterprise of deep history" (Chakrabarty 2009: 213). Let's recall the definition of deep history proposed by Edward Wilson to whom both Chakrabarty and Smail refer : "Human behavior is seen as the product not just of recorded history, ten thousand years recent, but of deep history, the combined genetic and cultural changes that created humanity over hundreds of [thousands of] years" (Wilson 1996 : ix-x).

According to Chakrabarty, biological "deep past" is certainly not deep enough though. In that sense, therefore, a "neurohistorical" approach to the Anthropocene remains insufficient. Neurocentrism is just a version of anthropocentrism. Focusing on the biological only, Smail would miss the geological dimension of the human: "Smail's book pursues possible connections between biology and culture - between the history of the human brain and cultural history, in particular, while being always sensitive to the limits of biological reasoning. But it is the history of human biology and not any recent theses about the newly acquired geological agency of humans that concerns Smail” (Chakrabarty 2009 : 206). The human recent status as a geological agent paradoxically draws the historian back to a very ancient past, a time when the human itself did not exist. A time that has thus to exceed "prehistory".

One will immediately argue that Smail, in his book, is precisely undertaking a deconstruction of the concept of prehistory. Clearly, the notion of deep history represents for him the result of such a deconstruction. Deep history then substitutes itself for prehistory. According to the usual view, history starts with the raise of civilization, and departs from a "buffer zone" between biological evolution and history proper - such a buffer zone is what precisely is called prehistory. If history must be understood, as Wilson suggests, as the originary intimate interaction between the genetic and the cultural, it starts with the beginning of hominization, and does not require any "pre" zone" (Smail: 2008).

Smail's approach is clearly an epigenetic one, which forbids to assimilate "hominization" with the history of consciousness. Epigenetics is a branch of molecular biology that studies the mechanisms that modify the function of genes by activating or deactivating them without altering the DNA sequence in the formation of the phenotype. Epigenetic modifications depend on two types of causes: internal and structural on the one hand; environmental on the other. Firstly, it is a 
matter of the physical and chemical mechanisms (RNA, nucleosome, methylation). Secondly, epigenetics also supplies genetic material with a means of reacting to the evolution of environmental conditions. The definition of phenotypical malleability proposed by the American biologist Mary-Jane West-Eberhard is eloquent in this respect: it is a matter of the "ability of an organism to react to an environmental input with a change in form, state, movement, or rate of activity" (West-Eberhard 2003:34). Contemporary epigenetics reintroduces the development of the individual into the heart of evolution, opening a new theoretical space called "evo-devo""evolutionary developmental biology."

In his book How Things Shape the Mind, A Theory of Material Engagement, Lambros Malafouris shows how epigenetics has modified the usual view of cognitive development, thus constituting cognitive archeology a major field in historical studies. "Cognitive development, he writes, is explained as the emergent product of these constraints [from genes and the individual cell to the physical and social environment]. In this context, the view of brain and cognitive development known as probabilistic epigenesis (...), which emphasizes the interactions between experience and gene expression (...), is of special interest. The unidirectional formula (prevalent in molecular biology) by which genes drive and determine behavior is replaced with a new scheme that explicitly recognizes the bidirectionality of influences between the genetic, behavioral, environmental, and socio-cultural levels of analysis" (Malafouris 2013:40).

This new scheme requires, as Malafouris brilliantly shows, a materialist approach of the interaction between the biological and the cultural. Hence the subtitle of the book : "A theory of material engagement". The epigenetic crossing and interaction in question here take place though things, through matter, that is also through the inorganic. It is a "non-representative" vision of interaction, which requires no subject-object relationship, no mind seeing in advance what has to be made or fabricated. Mind, brain, behaviour and the created object happen together, are part of the same process. "The cognitive life of things is not exhausted by their possible causal role in shaping some aspect of human intelligent behavior ; the cognitive life of things also embodies a crucial enactive and constitutive role" (Malafouris 2013 :44). Therefore, to explore the relationships between the brain and its "environment" is a much wider and deeper task than to study the role of the "human" in its "milieu", because precisely, it lays fondation, for an essential part, on a nonhuman materiality, and cannot be limited either to a biological kind of enquiry. In that sense, ecology to come acquires a new meaning : "this new ecology cannot be reduced to any of its constitutive elements (biological or artificial) and thus cannot be for by looking at the isolated properties of persons of things. The challenge for archeology, in this respect, is to reveal and articulate the variety of forms that cognitive extension can take and the diversity of feedback 
relationship between objects and the embodied brain as they become realized in different periods and cultural settings (...)” (Malafouris $2013: 82$ ).

Malafouris then argues that this ecology should be understood a a result of the "embedment" of the human brain. "The term 'embedment', Malafouris writes, derives form the fusion of the terms 'embodiment' - referring to the intrinsic relationship between brain and body — and 'embeddedness' — describing the intrisic relationship between brain/body and environment" (Mafouris $2010: 52$ ).

To conclude on that point and go back to our initial discussion, we can see that Smail's and Malafouris' approaches to brain/environment relationship are not "strictly" biological, but include, as a central element, the inorganic materiality of things. As Smail declares: "The great historical disciplines, including geology, evolutionary biology and ethology, archeology, historical linguistics and cosmology, all rely on evidence that has been extracted from things. Lumps of rocks, fossils, mitochondrial DNA, isotopes, behavioral patterns, potsherds, phonemes : all these things encode information about the past" (Smail 2008:57). Further: "History would be something that happens to people rather than something that people make" (Smail 2008:57).

Deep history, conjoined with archeology of the mind, or "neuroarcheology", would then extend the limits of the "brain" well beyond reflexivity and consciousness, well beyond "historicity" as well. As archeological, the brain/environment relationship is already also geological.

It remains clear though that Chakrabarty would not be entirely convinced by such an argument though. Even if non anthropocentric, even if thing- and inorganic matter- oriented, even if including at its core a neutral, a -reflexive, non-representative type of interaction as well as cognitive assemblages, the conjoined point of view of deep history and archeology of the mind still take the "human" as a point of departure. At least the "living being", and the process of hominization that is inseparable from the evolutionary perspective. Chakrabarty's perspective is very close to that of French philosopher Quentin Meillassoux in his book After Finitude. Meillassoux argues for a "non-correlationist" approach to the "real", that would not lay foundation on the subject-object relationship at all, and would totally elude the presence of the human on earth as a point of departure. There exists a mode of exploration of deep past (of the extremely deep past) that does not even consider the emergence of life in general as a "beginning". Deep past then become an "ancestrality" devoided of any "ancesters" : "I will call 'ancestral, Meillassoux writes, any reality anterior anterior to the emergence of the human species - or even anterior to any 
recognized form of life on earth" (Meillassoux 2008 :10). The archive, here, is not the object, not even the thing, not even the fossile, but what Meillassoux calls the arche-fossil : "I will call 'archefossil' or 'fossil-matter' not just materials indicating the traces of past life, according to the familiar sense of the term 'fossil', but materials indicating the existence of an ancestral reality or event ; one that is anterior to terrestrial life. An arche-fossil thus designates the material support on the basis of which the experiments that yield estimates of ancestral phenomena proceed - for example an isotope whose rate of radioactive decay we know, or the luminous emission of a star that informs us at to the date of its formation" (Meillassoux $2008: 10$ ). The world Meilassoux talks about is the Earth as being totally indifferent to our existence, anterior to any form of human presence — be it neural, be it neutral.

Again, these affirmations resonate with Chakrabarty's, who claims that the notion of "geological", in the expression "geological agent", forever remains outside human experience. "How does a social historian go about writing a human history of an unhabited and unhabitable vast expanse of snow and ice ?", he asks when talking about the Antarctic (Chakrabarty 2012 :12). A decorrelated subject cannot access itself as decorrelated. "We cannot ever experience ourselves as a geophysical force - though we now know, that this is one of the modes of our collective existence" (Chakrabarty 2012 :12). Chankrabarty's analysis adds something important to Meillassoux's thesis, for the reason that it takes into account the experience of the impossibility to experience decorrelationism. We can conceptualize it, but not experience it. "Who is the we ? We human never experience ourselves as a species. We can only intellectually comprehend or infer the existence of the human species but never experience it as such. There could be no phenomenology of us as a species. Even if we were to emotionally identify with a word like mankind, we would not know what being a species is, for, in species history, humans are only an instance of the concept species as indeed would be any other life form. But one never experiences being a concept" (Chakrabarty $2009: 220$ ).

At this point, a major issue appears, that relaunches the discussion and the necessity to come back to Smail's analysis. First, we don't see what a species can be outside the biological point of view. Why keep that term ? Second, I don't understand why the fact of becoming a geological form would have to remain entirely conceptual, and not produce a kind of mental phenomenon. "Climate scientists' history reminds us (...) that we now also have a mode of existence in which we collectively and as a geophysical force and in ways we cannot experience ourselves - are 'indifferent' or 'neutral' (I do not mean these as mental of experienced states) to questions of intrahuman justice" (Chakrabarty 2012 :14, emphasis mine). Before coming to the political consequences of such a statement, I would like to ask why precisely why could we not be 
susceptible to experience mentally and psychically the indifference and neutrality that have become parts of our nature ? Deprived of any empiricality, mental or psychic effects, the assumption of the human as a geological force remains a pure abstract argument, and in that sense, it appears as an ontological or metaphysical structure. Just like Meillassoux, Chakrabarty ends up failing to empiricize the very structure that is supposed to detranscendentalize, so to speak, the empirical. Why could, why should there be any intermediary locus of experience between consciousness and suspension of consciousness?

The brain asks for recognition at that point! Is not the brain, on which Chakrabarty remains totally silent, an essential intermediary between the historical, the biological, and the geological ? The site of experience we are looking for?

This brings us back to Smail and to one of the most important and interesting aspect of his analysis, the theory of addiction. Smail insists on the fact that the constant interaction between the brain and the environment is essentially based on brain-body states alterations. The brain maintains itself in its changing environment by getting addicted to it, and we have to understand "addiction" in the proper sense, that of a "psychotropy", a signicant transformation or alteration of the psyche. These altering effects result from the action of neurostransmitters "such as testosterone and other androgens, estrogen, serotonin, dopamine, endorphins, oxytocin, prolactin, vasopressin, epinephrine and so on. (...) Produced in glands and synapses throughout the body, these chemicals facilitate or block the signals passing along neural pathways" (Smail 2008 :113).

Such chemicals, which determine emotions, feelings, affects in general, can be modulated according to the demands of the behiavorial adaption they make possible. Adaptation, here, is twosided. It is of course adaptation to the external world, but it is also the adaptation of the brain to its own modifications.

All important changes in deep history, like the passage of an age to the other, has always produced new addictive processes and chemical bodily state modulations: "A neurohistorical model offers an equally grand explanatory paradigm, proposing that some of the direction we detect in recent history has been created by ongoing experiments with new psychotropic mechanisms that themselves evolved against the evolutionary backdrop of human neurophysiology. The Neolithic revolution between the 10,000 and 5,000 years ago transformed human ecology and led to fundamental and irreversible changes in demographics, politics, societies and economies. In this changing ecology, new mechanisms for modulating body states emerged through processes of undirected cultural evolution" (Smail 2008 : 187). We have to understand that "the expansion in calories available for human consumption, the domestication of animals useful as sources of energy, 
the practice of sedentism, the growing density of human settlements - such were the changes characteristic of the Neolithic revolution in all parts of the world where agriculture was partially invnted: Mesopotamia, Africa, China, Mesoamerica, and other sites. All these changes created, in effect, a new neurophysiological ecosystem, a field of evolutionary adaptation in which the sorts of customs and habits that generate new neural configurations or alter brain-body states could evolve in unpredictable ways" (Smail 2008:155).

From this, we get that obviously, "civilization did not bring an end to biology" (Smail 2008 :155). Again, deep history reveals the profound interaction of nature and history through the mediation of the brain as a both a biological and cultural adaptor. Human practices alter or affect brain-body chemistry, and in return, brain-body chemistry alter or affect human practices. Brain epigenetic power acts as a medium between its deep past and the environment.

"The mood-altering practices, Smail declares, behaviors, and institutions generated by human culture are what I refer to, collectively, as psychotropic mechanisms. Psychotropic is a strong word but no wholly inapt, for these mechanisms have neurochemical effects that are not all that dissimilar for those produced by the drugs normally called psychotropic or psychoactive" Smail 2008:161). Further: "Psychotropy comes in different forms: things we do that shape the moods of others; things we do ourselves; things we ingest" (Smail 2008:161).

We can distinguish here between autotropic and allotropic psychotropic, that is addictive substances and practices acting on the self, and addictive practices acting on the other, political addictive practices. Among the former are "coffee, sugar, chocolate, and tobacco" (Smail 2008:179), which first began circulating in Europe in the 17th and 18th centuries. “(...) All of these products have mildly addictive or mood-altering properties" (Smail 2008 :179). To these one will also add later alcohol and drugs.

Smail recalls that the current meaning of the term "addiction" emerged in the late XVII th century. "Earlier, the word had implied the state of being bound or indebted to a person — to a lord for example, or perhaps to the devil" (Smail 2008:183). This old meaning helps us understand what allotropy is. Psyhotropic addictive chemical mechanims can also be induced in subjects out of power excess and abuse of domination. Stress, and more generally affective states of dependence, all that Spinoza calls "sad passions", are essential aspects of this psychotropy, caused in contexts of dominance. The crossing point between modularity and change precisely coincides with the crossing point between biology and politics : "humans possess relatively plastic or manipulable neural states and brain-body chemistries", so that "moods, emotions, and predispositions inherited from the ancestral past" can be "violated, manipulated or modulated" (Smail 2008:117). 
According to Smail, autotropic and allotropic addictive processes automatically mark the point of indiscernability between biology (chemical substances and mechanisms) and culture (being-in-the-world). We find again the idea that the brain is the mediator between the two dimensions of (deep) history, natural and historical.

How can we extend these remarks to the current situation? First, they lead us to admit that only new addictions will help us to lessen the effects of climate change (eating differently, travelling differently, dressing differently...). Addictive processes have for a great part caused the Anthropocene, and only new addictions will be able to partly counter them. Second, they force us to elaborate a renewed concept of the addicted subject, of suspended consciousness and intermittent freedom. Third, they allow us to argue here that the neutrality Chakrabarty talks about is not conceivable outside a new psychotropy, a mental and psychic experience of the disaffection of experience. Such a psychotropy would precisely fill the gap between the transcendental structure of the geological dimension of the human and the practical disaffection of historical reflexivity. The man of the Anthropocene cannot but become addicted to its own indifference. Addicted to the concept it has become. And that happens in the brain.

The motif of a narcolepsy of consciousness, as both cause and effect of the technological destruction of nature, had already been interestingly and importantly suggested by Marshall Mc Luhan. His analyzes seems perfectly fitting the framework of the current ecological crisis. Technological development coincides for him with an extension of nervous system to the very limits of the world : "After three thousand years of explosion, by means of fragmentary and mechanical technologies, he writes, the Western world is imploding. During the mechanical ages we had extended our bodies in space. Today, after more than a century of electric technology, we have extended our central nervous system itself in a global embrace, abolishing both space and time as far as our planet is concerned" (Mc Luhan 1964:52). The extension of the nervous system to the world has a double contradictory effect, it acts as a pain killer (a "counter-irritant") to the extent that it suppresses all alterity, at the same time and for the same reason, it has a destructive power. Such is the structure of our "narcotic culture". Every technological device is a prolongation of the brain and the organism, and Mc Luhan characterizes this prolongation as a process of "auto-amputation" that precisely helps lower the pressure and creates anxiety, thus putting at work an economy of pleasure as "numbness".

One might argue that the world about which Mc Luhan talks, the world to which the nervous system extends its frontiers to is an image, a reflecting surface, whereas the split Chakrabarty analyzes as the separation between the human as a historical agent and the human as a geological force, confronts two definitely heterogeneous entities that cannot reflect each other at all. 
Nevertheless, if we look closely what Mc Luhan says about mirroring, narcissism, and the projection of one's own image, we see that reflection is for him immediately suspended by a spontaneous petrification, a geologization precisely, of both the gaze and the image. About the myth of Narcissus, Mc Luhan writes : "As counter-irritant, the image produces a generalized numbness or shock that declines recognition. Self-amputation forbids self-recognition” (Mc Luhan 1964:53).

Indifference and neutrality, once again, can be mental phenomena, even when their manifestations may seem totally alien to any mental or internalizing structure. Again, I don't think that the neutralization of consciousness due to its "geologization" can happen without the intermediary of brain processes resulting from its interaction with the world. I have tried to show elsewhere that indifference had become the global current "Stimmung" (Malabou 2008).

Such an interruption of consciousness or awareness, this indifference, directly challenge the concept of responsibility, which is of course central in our debate. How can we feel genuinely responsible for what we have done to the earth if such a deed is the result of an addicted and addictive slumber of responsibility itself? It seems impossible to produce a genuine awareness of addiction (awareness of addiction is always an addicted form of awareness). Only the setting of new addictions can help breaking old ones. Ecology has to be a new libidinal economy.

Here are some of the issues that political discourse on climate change, conferences like the one, the COP, that recently took place in Paris do not genuinely take into account, to the extent that the official ecological discourse, when it exists and is held by politicians who are not necessarily official ecologists, is still a discourse of awareness, "historicity" and responsibility. This of course does not mean that the human is not responsible for global warning. The anti-global warming movements themselves of course have their share of responsibility in global warming itself. Ignoring is a way to indirectly aggravate it. Nevertheless, the type of responsibility requested by the Anthropocene is extremely paradoxical and difficult to the extent that it implies the aknowledgment of an essential paralysis of responsibility.

Chakrabarty would no doubt argue that these last developements remain caught in the correlationist frame. They would still be human, all too human. Don't they let aside the issue of nature as such to only take into account humanity's techno-scientific power and its psychotropic causes and consequences?

"The traditional concept of history, Chakrabarty writes, implies a disavowal of the fact that nature can have a history. It presupposes a strict border between pure contingent facts (natural ones) and events understood as acts of agents. Croce, for example, claims that "there is no world but the human world" (Chakrabarty 2009:203). French historian Fernand Braudel, in his book The 
Mediterranean, of course rebelled against such a vision by taking into account the specific temporality of the Mediterranean natural environment, the soil, the biopshere, etc. Nevertheless, this time of nature is still seen as purely repetitive and mechanical, deprived of any agency or eventual power, it "is a history of constant repetition, ever-recurring cycles" (Chakrabarty 2009:204). Such a contention is not sustainable any longer, because the age of the Antrhopocene teaches something already wide spread in the "literature of global warming" : "the overall environment can sometimes reach a tipping point at which this slow and apparently timeless backdrop for human actions transforms itself with a speed that can only spell disasters for human beings" (Chakrabarty 2009:205).

What can we answer to this ? It is obvious that Braudel hasn't thematized or even perceived the historicity of nature, its mutability and ability to transform itself. In The Mediterranean and the Ancient World (Braudel 2001), the analysis of climate is definitely poor, as Braudel does not say a word, or at least nothing significant, about ecology. In that sense, Chakrabarty is right to challenge the cyclical vision of natural time that still governs Braudel's notion of nature's time and space. It seems to me though that Chakrabarty does not see how helpful Braudel nevertheless can be for our discussion. It is true that what Braudel calls the "geohistorical time", the archaic natural time, does not change. The "very long term" time, made of thousands of years, the geological time proper, seems to be deprived of any capacity to transform itself. But it is striking to note that the two other levels Braudel distinguishes, that of economic and social time (middle term duration) and that of the event (short term temporality), are also contaminated by the first level's immobility. And here is the interesting point. Braudel has perhaps failed to take into account the historical force of nature, but he certainly very early and accurately perceived the irrevocable naturalization of human history, that is of economic, political, and social time. He described better than anyone else the narcolepsy of historical temporality, to such a point that he got accused of de-politizing it.

Deconstructing the privilege of the event, Braudel showed that a geological principal, that of a blind slowing force, was operating at all layers of time. In that sense, he anticipated something from the current situation, to the extent that he announced that historical consciousness had to aknowledge its own naturalization and suspension by entering the reign of immobility. In that sense, what Chakrabarty sees as a result (the human transformed into a geological force because of climate change and the entry into the Anthropocene), Braudel saw as a beginning (history has always already slowed down, thus preparing itself to its own neutralization by nature). What he said about capitalism is extremely interesting in this respect. He argued that material life progresses by means 
of "slow evolutions". Advances occur "very slowly over long periods by the initiative or groups of men, not individuals (...), and in countless and obscure ways" (Braudel 1973: 258). Great technical revolutions infiltrate society "slowly and with difficulty... to speak of revolution here is to use a figure of speech. Nothing took place at break-neck speed" (Braudel 1973: 442).

One might object again here that long term temporality presupposes an essential passivity and unchangeability of nature, that it can't account for a sudden constitution of nature itself as a historical acting agent, like the one we are currently witnessing with the Anthropocene. This is true. But the problem, as we have seen all along, is that approaching the historical force of nature paradoxically leads us to slow down, to face the suspension of consciousness, the numbness and slumber of our responsibility. It is in a certain sense like exchanging roles, nature becoming historical and the anthropos becoming natural. This exchange constitutes a new form of human experience, and this Braudel helps us to conceptualize.

The third generation of the Annales School in France : Marc Ferro, Jacques Le Goff, Emmanuel Leroy-Ladurie still increased the part played by the very long term temporality. As one of them declares : "Time is fully human, and yet, it is as motionless as geographic evolution" (Dosse 1987 :165). Braudel's work found itself extended and prolongated by the introduction of an important concept that emerged at that time in historical science, that of "mentality", closer to the psychological than to the intellectual. The taking into account of slow time, long term time, gave way to an "history of mentalities" (histoire des mentalités). Based on "material culture", that is on the similarities between the mind's rythms and natural cycles, history of mentalities provided its readers with descriptions and analyses of uses, repetitions, habits, and representations. ${ }^{i}$ Philippe Aries declared that history of mentalities situated itself "at the crossing point between the biological and the social" (Aries 1981, Dosse 1987:198).

As we already noticed, this crossing point between the biological and the social does not mean that the biological must be taken as a point of departure, or that the human as a living being should become the origin of historical research. The history of mentality also includes, as one of essential dimension, the materiality of inorganic nature, the soil, the rocks, the mountains, the rivers, the Earth. A mentality is a hybrid concept that comprehends not only the psychic and the social, but also the originary likeliness of the mind and the fossil, the inscription of naturality in thoughts and behaviours. Mentality, in that sense, is rooted in the brain and not in consciousness. "The human reduced to its "mental" is the object rather than the subject of its own history (l'homme réduit à son mental est objet de son histoire plutôt que sujet)" (Dosse 1987:206). Jean Delumeau, author of the important La Peur en occident (Sin and Fear: The Emergence of a Western Guilt Culture, 13th-18th Centuries), writes, while playing with the multiple sense of the term 
“natural": "Fear is natural" (Delumeau 1990, Dosse 1981:206). As a consequence of all previous analyses, we may consider history of mentalities to be the first form of environmental studies in France. Could it be that a new form of histories of mentalities, that would bring together the geological, biological and cultural current dimensions of historical (non)awareness, may open a new chapter of these studies?

What seems to me challengeable in Chakrabarty's is the claim of an impossibility to phenomenalize the geological becoming of the human. This "species" the human has become remains a pure void concept until it can be filled with intuition, that is with an empirical and sensuous content, if not with awareness. A renewed and reelaborated concept of mentality might precisely help providing the missing content of this form. There necessarily exists a mental effect of the numbness and paralysis of consciousness, a mental effect of the new narcoleptic structure of humanity's (impossible) reflection on itself. We have seen, with Smail and Mc Luhan, that this mental effect was a neural one in the first place. Again, it is not a matter of thinking the brain "in" its environment, it's a matter of seeing the brain as an environment, as a metabolic place. Therefore, I prefer using the term "mental" rather than "neural", because "mental" immediately evokes the merging and mingling of different registers of materialities. In that sense, for us getting used to the new condition of the human as a geological agent will of course require a new mentality, that is new addictions, new bodily adaptations to an inorganic and earthly corporeity, a new natural history. A history, still, nevertheless.

Reading Braudel and his followers helps us perceive that the narcolepsy of consciousness constitutes an irreducible dimension of history. Long term temporality, immobility, very slow evolution show that deep history has always been inscribed at the heart of history, as this numbness of time and action that submits cultural evolution to a geophysical rythm. Braudel is perhaps not a thinker of climate change, but he his a great theoretician of a new form of Marxism that binds the critique of capital to a study of the irreducible naturality, neutrality and passivity of time. The critique addressed to the historians of long term duration and mentalities were about the same that the ones currently addressed to Chakrabarty, all pointing, in both cases, at a supposed depolitization of history. François Dosse wrote that with the Ecole des Annales, in the end, "history ha[d] negated itself". He wished that "the event" might come back in order to wake up time from its geological slumber (Dosse 1981:258) ... He could not foresee that with the Anthropocene, long term 
temporality would precisely acquire the status of an event — which would free the attempt at thinking ecology and politics differently.

Aries, Philippe. 1982. The Hour of Our Death, The Classic History of Western Attitudes Toward Death over the Last One Thousand Years. Translated by Helen Weaver, New York : Vintage Books.

Bonneuil, Christophe Fressoz, Jean-Baptiste. 2016. The Schock of the Anthropocene. Translated by David Fernbach. London :Verso.

Braudel, Fernand.

The Mediterranean and the Ancient World. 2001. Translated by Sian Reynolds. London:Pinguin Books. Afterthoughts on Material Civilization and Capitalism (The Johns Hopkins Symposia in Comparative History). 1977. Translated by Patricia Ranum, Baltimore : Johns Hopkins University Press.

Press.

On History, 1980. Translated by Sarah Matthews. Chicago : The University of Chicago

Capitalism and Material Life 1400-1800. 1973. New York: Harper and Row.

Chakrabarty, Dipesh.

2009. "The Climate of History :Four Theses", Critical Inquiry

Vol. 35, No. 2. 197-222.

2012. "Postcolonial Studies and the Challenge of Climate Change", New Literary History,

Baltimore : John Hopkins University Press, vol. 43, Number 1, Winter 2012, 1-18.

Delumeau, Jean. 1990. Sin and Fear: The Emergence of a Western Guilt Culture, 13th-18th Centuries tr. Eric Nicholson. Chicago:The University of Chicago Press.

Dosse, François. 1987. L'Histoire en miettes, Des Annales à la nouvelle histoire, Paris:La Découverte.

Malabou, Catherine. 2012. The New Wounded, From Neurosis to Brain Damage. Translated by Sreven Miller. New York: Fordham.

Malafouris, Lambros.

2010."Metaplasticity and the Human Becoming: Principles of Neuroarcheology”, Journal of Anthropological Science. Vol. 88. 49-72.

2013.How Things Shape the Mind, A Theory of Material Engagement. Boston: MIT Press.

Mc Luhan, Marshall. 1964 (1990). Understanding Media, The Extensions of Man, New York : St Martin's Press.

Meillassoux, Quentin. 2008. After Finitude: An Essay On the Necessity Of Contingency. Translated by Ray Brassier, London:Continuum. 
Smail, Daniel Lord. 2008. On Deep History and the Brain. Berkeley : University of California Press.

West-Eberhard, Mary-Jane. 2003. Developmental Plasticity and Evolution. New York: Oxford University Press.

Wilson, Edward. 1996. In Search of Nature. Washington D.C: Island Press. 